\title{
GLOBALIZACIÓN Y TURISMO EN EL SUR DE QUINTANA ROO
}

\author{
Magalí Daltabuit Godás \\ Centro Regional de Investigaciones Multidisciplinarias, UNAM \\ Héctor Cisneros Reyes \\ Instituto de Investigaciones Antropológicas, UNAM \\ ERnesto Valenzuela Valdivieso \\ Instituto de Geografía, UNAM
}

\section{Introducción}

El concepto de globalización resulta difícil de concretar, pues se le han dado distintos significados. Se ha usado como parte del discurso académico, como un término de la mercadotecnia, como un eslogan político, como frase periodística o como término que está "de moda" en el nuevo siglo. lanni (1999) explica que hay distintas metáforas, así como interpretaciones fundamentadas, que aparecen en la bibliografía sobre la globalización, como son: "economíamundo", "sistema mundo", "shopping center global", "disneylandia global", "capitalismo global", "fábrica global", supraterritorialidad, etcétera. Cada una de estas interpretaciones tiene ángulos diversos de análisis, que parten de distintas disciplinas y se enfocan a aspectos sociales, económicos, políticos, geográficos, históricos, culturales y religiosos, entre otros.

Se puede decir que han existido dos corrientes principales en el análisis de la globalización. Por un lado, los autores que parten del materialismo histórico han interpretado el surgimiento de la globalización como una fase particular del desarrollo capitalista, entendiéndolo como un proceso a la vez social, económico, político y cultural, complejo y contradictorio, que rebasa fronteras geográficas e históricas, modos de vida, culturas y civilizaciones. Esta corriente explica que desde un principio, el capitalismo se revela como un modo de producción internacional. A lo largo de su historia, desde el siglo xvı, siempre traspasó fronteras de todo tipo e influyó decisivamente en la economía del mundo desde el desarrollo de la acumulación original, el mercantilismo, el colonialismo, el imperialismo, el multinacionalismo, el transnacionalismo y el neoliberalismo (Ianni, op. cit.). Para finales del siglo xx, el modo capitalista de producción entra en una época propiamente global, y no internacional o multinacional. Hay una transformación cuantitativa y cualitativa del capitalismo, más allá de todas las 
fronteras, que va subsumiendo las demás formas de organización social y de producción.

Por otro lado, las narrativas postmodernas o postestructuralistas se han centrado en la transformación sociocultural que ha ocasionado la globalización. Scholte (1997) la define como el proceso por el cual un dominio de supraterritorialidad se ha sumado al espacio social, creando una dimensión transmundial de las relaciones sociales. La globalidad introduce una nueva calidad de espacio social, que es no territorial y sin distancias. Es una poderosa fuerza que reduce el espacio y aumenta la movilidad del capital, de las personas, las ideas y la información a escala universal. El tiempo-espacio se ha comprimido como resultado de la tecnología, lo que ha tenido el efecto de "apartar la vida social de las fijaciones de la tradición", de tal manera que las prácticas sociales locales se ven superadas por el poder de las relaciones económicas globales.

El contraargumento de algunos autores es que las particularidades locales, culturas e identidades siempre prevalecen porque existen como "barreras geopolíticas" de las civilizaciones modernas (Teo y Hiong Li, 2003: 2). Apuntan que la globalización no es un proceso lineal irreversible, ni se puede sostener que constituya la única fuerza o la fuerza primaria de la historia contemporánea. Los territorios, la distancia, las fronteras y los estados nacionales aún no han perdido todo significado en el actual mundo globalizado.

Dentro del neoliberalismo se acepta una realidad de globalización como un proceso progresivo y benigno. Se dice que la globalización contemporánea ofrece el prospecto de finalmente cumplir la promesa de la modernidad. Sin embargo hay evidencia de que con frecuencia ha perpetuado, y en algunos casos incrementado, la pobreza, la violencia y la degradación ambiental. Hay que considerar que la globalización no ha tocado a cada persona, localidad o región del planeta en la misma medida, es decir que no todos disfrutan de un acceso o una voz igualitaria en este proceso.

Podemos ver, según datos recientes de la CEPAL, que la larga crisis y el costo social de los modelos neoliberales aplicados en los años noventa agudizaron la pobreza en Latinoamérica. Casi 91 millones de personas se convirtieron en pobres en los últimos 20 años. No sólo aumentó la cantidad de pobres en términos absolutos, sino que también hubo un claro crecimiento de la indigencia o miseria extrema: ahora hay 40 millones más de indigentes que hace dos décadas. Eso significa que 102 millones de personas en Latinoamérica no tienen los ingresos requeridos para consumir el mínimo de proteínas y calorías necesarias para vivir.

Ecológicamente, en las últimas décadas la globalización se ha concretado en el cambio climático del planeta, el adelgazamiento de la capa de ozono, la perdida de la biodiversidad y la degradación ambiental. Es ante esta crisis ambiental global cuando surge la propuesta del desarrollo sustentable. Hay que recordar que el discurso del desarrollo sustentable, incorporado en los procesos globales actuales, plantea las metas de mejorar las condiciones de vida y lograr 
la protección al medio ambiente, permitiendo continuar con el modelo de desarrollo y crecimiento económico a través de estrategias de manejo adecuadas. Dentro del discurso del desarrollo sustentable, los conceptos de planificación y manejo incorporan la creencia de que el cambio social se puede diseñar, dirigir y producir a voluntad.

De esta manera, una de las grandes preocupaciones actuales de las agencias internacionales es cómo integrar los procesos y sociedades locales en estos proyectos de desarrollo sustentable. Se trata de encontrar la manera de relacionar los veloces procesos de desarrollo a escala global con la dinámica de las poblaciones locales, y de compaginar el rápido crecimiento económico con el bienestar de dicha población y con el cuidado del medio ambiente natural.

\section{El turismo como industria global}

Actualmente, dentro del proceso de globalización económica, el turismo es una de las mayores industrias a nivel mundial; sin duda una parte de las fuerzas macroeconómicas de la globalización. Se le ha considerado como elemento "hiperglobalizador", y es visto como uno de los factores más significativos en la homogeneización, hibridación y sincretismo en el mundo.

Considerando que el turismo se basa en el uso y la apropiación de recursos naturales, y enmarcado dentro del discurso del desarrollo sustentable, durante las últimas décadas se ha sumado una nueva dimensión a esta industria: el ecoturismo. Esta modalidad de turismo sustentable supone ser más sensible y provocar menos efectos negativos en el medio ambiente natural y en la cultura local que el turismo masivo (Brandon, 1993). El ecoturismo se ha propuesto a los países del Tercer Mundo y ha sido promovido por las agencias internacionales (Banco Mundial y Fondo Monetario Internacional) como una alternativa de desarrollo que provee beneficios ambientales, socioeconómicos y culturales, tanto a nivel local como nacional. Se ha entendido como un elemento importante del desarrollo sustentable, que une al crecimiento económico con la conservación de los recursos naturales, siguiendo los principios de manejo propuestos por las organizaciones internacionales. De esta manera la ONU declaró al 2002 como el "año del ecoturismo".

En México, durante la última década se han desarrollado políticas nacionales y regionales que siguen los lineamientos de estas instituciones internacionales. La propia experiencia del sureste mexicano ha desempeñado un papel importante en la formulación de la concepción de los nuevos criterios para el desarrollo elaborados por los organismos internacionales y en su puesta en marcha en nuestro país, resaltando los de sustentabilidad ambiental, económica y social para lograr la mejoría en la calidad de vida de la población.

Es precisamente dentro de este contexto de globalización y sustentabilidad donde se plantea ahora el desarrollo regional del sur del estado de Quintana Roo, 
basado en el turismo sustentable. Por consiguiente, esta región representa un buen ejemplo para observar la relación local-global, ya que el Gobierno del estado, apoyado por organismos internacionales, está llevando a cabo el desarrollo del turismo sustentable en esta región, involucrando a diversas comunidades locales, a través de los proyectos Costa Maya y el Corredor Ecoarqueológico.

Esta región, hasta hace poco tiempo aislada y escasamente poblada con pequeñas comunidades mayas, se forma a partir de la confluencia de personas de muy distintos lugares. El desarrollo turístico en el estado ha ocasionado un amplio movimiento de inmigración de los estados vecinos, de diversas regiones del territorio nacional y del extranjero. Las personas que han llegado a vivir a Quintana Roo proceden de distintos estratos sociales y tienen diferentes estilos de vida, por lo que hay gran diversidad entre los actores sociales de la región. Los extranjeros, tanto los turistas como los inversionistas, contribuyen a hacer aún más heterogénea la situación.

Considerando estos antecedentes, un grupo de investigadores de la UNAM nos planteamos llevar a cabo una investigación con el objetivo de estudiar grupos sociales inmersos en una trama compleja de transformaciones, que está configurada dentro del contexto de la globalización a través de la industria turística en el sur de Quintana Roo, y valorar de acuerdo con las experiencias en la zona las diversas formas de integración de las comunidades al desarrollo del turismo sustentable de la región. Se analiza su aportación a la conservación ambiental, mejoramiento de las condiciones de vida de la población, y el respeto y desarrollo de las culturas locales para llegar a una verdadera sustentabilidad.

La metodología utilizada para lograr estos objetivos consistió en la aplicación sistemática de distintos instrumentos para recopilar información tanto de tipo cuantitativo, a través de encuestas a hogares, así como cualitativo por medio de entrevistas e historias de vida en las comunidades de estudio.

En este estudio nos enfrentamos a lo que Hernán Salas define como "el reto actual de la antropología", que es precisamente analizar las relaciones entre esta diversidad de protagonistas y entender el amplio rango de actores sociales y de sus intereses. Menciona Salas que "la antropología ofrece la oportunidad de recrear conceptos claves de la disciplina para la comprensión de la relación entre lo local y lo global, es decir, una antropología de los grupos locales en un contexto de configuraciones globales; y de la globalidad vista desde las localidades, pero sobre todo de la relación que éstas entrañan" (Salas, 2002).

El turismo es un buen ejemplo de la interacción entre grupos sociales que emanan de distintas escalas: internacional, nacional, regional y local. Muestra las tensiones en las relaciones de poder que se originan en el escenario local y global. Ciertos autores argumentan que los habitantes locales se apropian del turismo y lo usan para reconstruir simbólicamente su cultura, sus tradiciones y 
su identidad. De tal manera, la globalización no debe verse como preponderante sino mediada siempre por los factores locales, que producen resultados únicos en las diferentes localidades.

Uno de los objetivos de la investigación es analizar las interrelaciones entre los actores sociales involucrados en el desarrollo del turismo sustentable en el sur de Quintana Roo, tratando de resaltar las diferencias entre las respuestas locales de tres comunidades a este proceso regional, inmerso en la dinámica global.

Los actores sociales incluyen personas, instituciones y grupos sociales involucrados o bien que se ven afectados por la toma de decisiones referentes a los temas sobre el desarrollo del turismo y la sustentabilidad, tanto a nivel local como regional, nacional e internacional. Se pueden definir como grupos o categorías de personas que ganan o pierden derechos y/o recursos a través de los procesos de desarrollo turístico. Entre las categorías de actores sociales involucrados en el desarrollo del sur de Quintana Roo están actores internacionales (agencias internacionales, las ONG, organizaciones sociales, corporaciones transnacionales), actores nacionales (gobiernos nacionales, la iniciativa privada, ONG nacionales o regionales) y actores locales (pobladores, autoridades y administradores regionales).

En realidad, el capital global, las instituciones supranacionales y otros procesos económicos están inmersos en localidades específicas, que tienen relaciones sociales localmente constituidas, como los lazos comunitarios, tradiciones culturales y relaciones de poder que van a determinar las formas en las que la globalización se va a concretar y cómo la localidad va a responder. En resumen, las particularidades locales, la cultura y las identidades se yuxtaponen con las influencias globales, y producen resultados únicos (Teo y Hiong Li, op. cit.).

\section{El turismo sustentable en el sur de Quintana Roo}

Analizamos en particular el interesante caso de un nuevo proyecto de impacto regional en el sur del estado de Quintana Roo, que está enfocado al ecoturismo. La zona del sur de Quintana Roo cuenta con una importante riqueza biológica y cultural, por lo que se han decretado en ella áreas naturales y culturales protegidas; en consecuencia, la sustentabilidad ambiental es una condición primordial para este proyecto. Específicamente nos centramos en un análisis comparativo de los proyectos de desarrollo turístico llamados "Costa Maya" y "Corredor Ecoarqueológico", y en particular en la integración de los habitantes locales a estos nuevos proyectos de desarrollo sustentable (mapa 1).

Los antecedentes históricos de la Costa Maya y de la zona del Corredor Ecoarqueológico nos muestran la situación en el sur de Quintana Roo, a lo largo del siglo xx, como una región donde los recursos naturales siempre han sido 


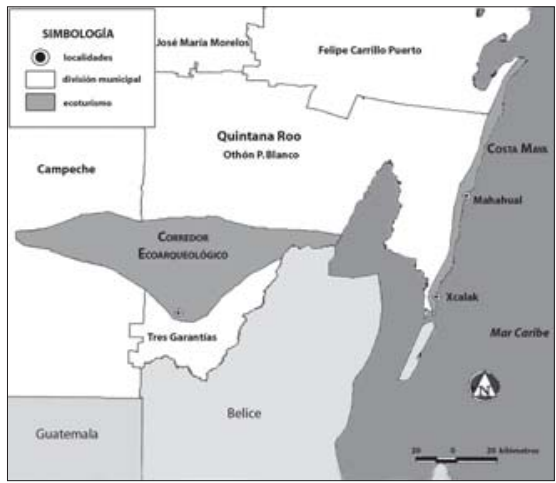

Mapa 1. Comunidades estudiadas

FuENTE: INEGI 2000. División municipal de México. Obtenido del Marco Geoestadístico Municipal 2000. Escala 1:1000 000. Editado por el Centro Regional de Investigaciones Multidisciplinarias, CRIM, UNAM, México.

de suma importancia para la economía de sus pobladores. Desde principios de siglo, las principales actividades económicas fueron, en la costa sur, la copra y la pesca, y en la zona de la selva, la explotación forestal, en particular del chicle y las maderas preciosas. Para los años setenta empieza a desarrollarse el turismo en el norte del estado, con apoyo de agencias internacionales, y desde entonces el impacto de esta industria en la estructura económica de Quintana Roo fue radical, ubicándola como el principal motor de desarrollo. Actualmente la industria turística del estado es la más importante del país, y es innegable que ha generado beneficios económicos tanto a nivel estatal como nacional. Sin embargo la región sur del estado estuvo marginada del auge del turismo hasta principios de los años noventa, cuando inicia el proyecto regional de ecoturismo con el objetivo de lograr un desarrollo socioeconómico sustentado en la protección de los recursos naturales.

El Proyecto Costa Maya es un plan gubernamental para desarrollar ecoturísticamente la costa sur del estado, comprendida entre Xcalak y Punta Herrero, 
con un total de $130 \mathrm{~km}$, en los que se pretenden desarrollar 18 centros turísticos con una inversión de mil millones de dólares por medio del Fideicomiso Costa Maya (Fidecaribe), que se dice beneficiará a la zona con infraestructura, plusvalía y capitalización. Fidecaribe ha trazado los mapas, realizado el deslinde e instalado la infraestructura básica de la Costa Maya construyendo tres aeropistas, muelles y la carretera que va de Mahahual a Xcalak. Tiene además la facultad de comercializar los terrenos, ofrecer asesoría técnica sobre financiamientos disponibles y los permisos requeridos para poder proceder a la urbanización.

El Corredor ecoarqueológico o Corredor Río Bec forma parte del plan de desarrollo turístico del sur de Quintana Roo. Es la continuación en la zona continental del corredor Costa Maya, y es un circuito de turismo alternativo de base cultural y de observación de la naturaleza, que abarca los estados de Quintana Roo y Campeche y une a la reserva de Sian Ka'an con la de Calakmul. Comienza desde Escarcega hasta Bacalar, y en su ruta están varios sitios arqueológicos y coloniales importantes, como son Oxtankah, Kohunlich, Dzibanché, Kinichná, Xpujil, Becan, Chicanná y Calakmul. Este corredor está comenzando a operar a partir de nuevos hoteles y campings aledaños a zonas arqueológicas, y de centros de desarrollo turístico comunitarios en los que se ofrecen caminatas en la selva, además de observación de aves y animales silvestres, entre otros atractivos. Existen también reservas forestales en comunidades de esta zona que empiezan a ser un destino para los ecoturistas en el sur del estado. El tipo de desarrollo turístico que se prevé para el sur de Quintana Roo en su totalidad es de bajo impacto y baja densidad. Esto significa pequeños grupos que visiten las reservas, las playas, los arrecifes, los sitios arqueológicos y los poblados mayas (Fidecaribe, 2000).

Se seleccionaron para este estudio dos comunidades en la Costa Maya que son Xcalak y Mahahual, y una en el Corredor Ecoarqueológico, Tres Garantías, ubicadas todas ellas en el municipio de Othón P. Blanco.

\section{Costa Maya}

Los primeros habitantes de la costa sur de Quintana Roo fueron mayas que llegaron por el mar Caribe. Su presencia se remonta al arribo de los putunes o mayas chontales que venían desde el actual Tabasco. Muchos pequeños poblados costeros se encontraban a lo largo de las rutas comerciales que llegaban hasta Honduras. Participaban con sal y pescado en el intenso comercio existente en esa época en la región, lo que les permitía subsistir a pesar de las tierras pobres para la agricultura, brindándoles diversos tipos de recursos, en especial alimenticios (Martos, 2002).

Los asentamientos prehispánicos en Costa Maya han sido poco estudiados, pero se han descrito 17 sitios con pequeños asentamientos, adoratorios y evi- 
dencias de concheros. La ocupación más temprana detectada corresponde al período Preclásico Tardío (300 a.C. - 300 d.C.). ${ }^{1}$

En 1527 arribaron a las costas de lo que hoy es Quintana Roo las primeras expediciones españolas al mando de Francisco Montejo. Desde el siglo xvı y hasta finales del siglo xix, la zona fue acosada por piratas ingleses, quienes atacaban los barcos que transportaban oro y riquezas hacia España. Para principios del siglo xx podemos establecer que la zona de la costa maya fue importante para la comercialización de chicle, y poco después se constituyó como un área de alta producción coprera (extracción de aceite de coco), la cual representó la actividad económica más importante. Sin embargo, y debido al paso del huracán Janet, a mediados de los cincuenta, la zona fue prácticamente abandonada y vuelta a repoblar una vez que se abrió la carretera que hoy existe. La pesca se constituyó entonces como la principal actividad económica. Dicha actividad generó la organización de los pobladores en cooperativas para la extracción de caracol y langosta.

A principios del año 2000 esta región costera tenía tres centros poblacionales: Mahahual, Xcalak y Punta Herrero, con un total de aproximadamente 1500 habitantes, que se dedicaban principalmente a la pesca comercial. En la zona existen tres cooperativas, dos en Mahahual: Banco Chinchorro y Langosteros del Caribe, y una en Xcalak: Andrés Quintana Roo. Existen también agrupaciones de pescadores libres, así como agrupaciones de escameros. Desde hace alrededor de diez años empieza la actividad turística en la zona, teniendo un desarrollo incipiente hasta 1994, momento en que se concreta el proyecto Costa Maya (mapa 2).

\section{Xcalak}

Xcalak es el puerto más antiguo de Quintana Roo, pues se funda en 1900, convirtiéndose en el primer astillero del Caribe mexicano. En esa época, esta comunidad era el único pueblo que no vivía de la caoba ni del chicle, sino de la explotación del coco y la pesca. Poco a poco la copra fue desplazando a la pesca como actividad económica; ya para la década de los treinta era el producto comercial más importante de la costa del Caribe. Es en este momento cuando Xcalak tiene un gran auge comercial y en infraestructura portuaria, convirtiéndose en una comunidad de importancia en Quintana Roo. Sin embargo, en 1937 el precio del producto se vino abajo, por lo que se intensificó la pesca, y en 1941 fundaron la primera cooperativa de todo el estado para dedicarse a la cap-

\footnotetext{
${ }^{1}$ En un reconocimiento arqueológico en 1991, desde Punta Herrero hasta Xcalak se describieron 17 sitios: Canché Balam, Tampalam, San Lorenzo, San Antonio, Río Indio, Punta Xocoxh, La Armada, Guadalupe, Eric Villanueva, Río Huach, Punta Hobná, Punta Gavilán, La Curve, Siete Cocos, Xcalak, Cementerio Xcalak y Necax
} 


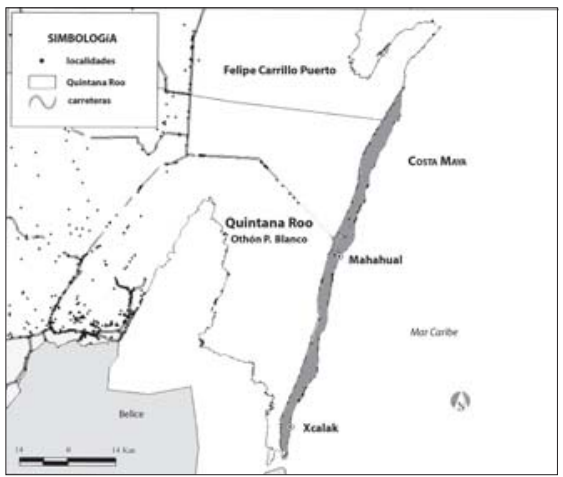

Mapa 2. Mahahual y XCalak. Localización en Quintana Roo

tura de tiburón. Un parteaguas en la historia de Xcalak fue el ciclón Janet, de 1955, que arrasó a la comunidad destruyendo las plantaciones de coco y ocasionando la emigración de un gran número de sus habitantes.

A finales de la década de los ochenta y principios de los noventa comenzó un nuevo período en el desarrollo de Xcalak, a través del turismo, con una oferta que incluye el buceo, la pesca deportiva y el ecoturismo. Se considera como uno de los sitios de mayor potencial ecoturístico dentro del Proyecto Costa Maya, pero hasta ahora el desarrollo ha sido incipiente y aún no llegan los servicios públicos necesarios.

Xcalak tiene actualmente 276 habitantes que habitan en 69 viviendas. A diferencia de otras comunidades quintanarroenses, la gran mayoría de los pobladores es nacida en la entidad. La carencia de servicios públicos (agua, electricidad, drenaje) hace que la calidad de vida de sus habitantes se vea afectada.

La pesca sigue siendo el sustento básico para más de la mitad de las familias de la comunidad. Otra actividad importante para varias personas es el turismo, y otras se dedican al comercio, a la albañilería y a la agricultura.

Actualmente existen en Xcalak siete ecohoteles, cinco restaurantes, cuatro tiendas y una tienda de buceo. De los hoteles sólo uno se ubica dentro del nú- 
cleo urbano de la comunidad; pertenece a la cooperativa pesquera y tiene precios accesibles para los turistas nacionales. Los demás ecohoteles, en donde se alojan turistas extranjeros, son todos de inversionistas extranjeros, en un caso con copropietarios locales.

Aunque entre los vecinos de Xcalak se aprecia una diferenciación social y económica, no es una comunidad muy heterogénea. La mayoría de los habitantes son nacidos en Quintana Roo (68.7\%). Las actividades económicas no son tan diversificadas, y hay más homogeneidad en cuanto a la escolaridad de sus pobladores. Existen varios actores sociales, locales y de otros sectores, como el gubernamental, los inversionistas privados extranjeros, las ONG y organismos internacionales, que influyen en la vida de la comunidad.

Los actores locales con mayor fuerza son los miembros de la cooperativa pesquera Andrés Quintana Roo y la cooperativa turística. Existe una rivalidad entre estos grupos y los pescadores libres, ya que se acusan mutuamente de no respetar las vedas y las áreas asignadas para la pesca dentro de las áreas naturales protegidas.

Actualmente en Xcalak el principal conflicto se da entre los habitantes locales y los inversionistas extranjeros, así como entre estos dos actores y el Estado, representado en este caso por el Fidecaribe, la Secretaría de Turismo (Sectur) y la Secretaría de Medio Ambiente y Recursos Naturales (Semarnat). Hay que observar que ha habido incidentes entre Fidecaribe y los inversionistas de la Costa Maya. Han existido denuncias por parte de inversionistas que acusan de extorsión a Fidecaribe y varios empresarios que se quejan de que se les cobran multas ilegalmente.

En Xcalak, comunidad que se encuentra todavía marginada del desarrollo turístico, nos mencionan en las entrevistas sobre el proyecto Costa Maya y Fidecaribe que "Hasta ahora no hay nada concreto, no hemos visto nada de la Costa Maya. Oímos del Gobierno, pero no hay servicios".

Otro testimonio nos deja ver que hay tensión con Fidecaribe, pues dicen que: "El Gobierno se va a quedar con todo. Ya vio lo que tienes y te lo quieren quitar. Estamos peligrando. No nos conviene. Fidecaribe ha sido una dependencia del Gobierno que ha perjudicado mucho, mucho. La gente de aquí muchos años atrás tenía sus terrenos acá en la costa, no los legalizaron, y ahorita se los están quitando".

Otro habitante señaló: "Los inversionistas son los que se benefician más del ecoturismo, pues tienen los hoteles, el equipo. Pienso que el ecoturismo sí va a ser una actividad importante en Xcalak. Hay que ponernos las pilas para que nos toque algo".

Otro grupo de actores es el de los ambientalistas, en este caso representados por Amigos de Sian Ka'an A. C., la World Wildlife Fund y la Universidad de Rhode Island, quienes han apoyado y asesorado a los habitantes locales en la creación del Parque Marino Arrecifes de Xcalak, y han desarrollado programas de capacitación y de educación ambiental que han creado una conciencia en 
los habitantes locales sobre la importancia de la protección de los recursos naturales.

Por otro lado, a las autoridades de la Secretaría de Turismo estatal les interesa impulsar el desarrollo económico regional por medio del turismo sustentable con el proyecto Costa Maya. Las autoridades del medio ambiente centran su atención en la protección de los recursos naturales por medio de las áreas naturales protegidas (ANP) que han sido decretadas en la región: Reserva de la Biosfera Banco Chinchorro y Parque Marino Arrecife de Xcalak. Los planes de manejo señalan los reglamentos para el funcionamiento de estas ANP. En algunas ocasiones los intereses de estas dos secretarías entran en conflicto.

\section{Mahahual}

A principios de siglo, en la zona donde actualmente se ubica Mahahual había solamente ranchos copreros, en los que llegaron a vivir más de 10 familias dedicadas a la producción de copra. El paso del huracán Janet por el sur de Quintana Roo ocasionó la perdida y destrucción de los cocales y el consecuente abandono del rancho en Mahahual. No es sino en los años ochenta cuando la comunidad de pescadores de Xcalak solicita al Gobierno del estado un terreno donde construir un campamento pesquero, y queda establecido en Mahahual, lo que da origen a la comunidad de pescadores que actualmente se asienta en esta localidad.

Mahahual cuenta con 127 habitantes integrados en 36 hogares. La mayoría proviene de otras poblaciones de Quintana Roo, en particular de otros estados de la República, como Veracruz, Campeche y Yucatán, y se dedica a la pesca.

Las actividades turísticas se iniciaron hace alrededor de una década de manera incipiente, pero es a partir de 1997, con el proyecto de Costa Maya, cuando se desarrollan más, en particular se empiezan a construir cabañas y bungalows. También ya funcionan dos hoteles. Al turismo se dedica $13 \%$ de la población, básicamente restauranteros. Otra actividad es el comercio, al que se dedica apenas $9 \%$ de los habitantes.

El Proyecto Costa Maya ha tenido un mayor impacto en Mahahual, ya que en febrero del 2001 se inauguró el nuevo Puerto Costa Maya. Se trata de un muelle y una terminal de cruceros que fueron concesionados por la Secretaría de Comunicaciones y Transportes a la empresa privada de capital multinacional (mexicano, holandés y noruego) Promociones Turísticas Mahahual. Esta misma empresa planea hacer un poblado para 20000 habitantes en un área de 1.5 millones de $\mathrm{m}^{2}$, así como hoteles (12000 cuartos), zona comercial, plantas de tratamiento de agua, etcétera. Ya están listas las primeras 250 casas y se irán construyendo otras 250 cada año.

En cada crucero llegan entre 1500 y 3000 pasajeros. Se calcula que durante el 2002 llegaron a Mahahual alrededor de 400000 pasajeros. Actualmente el 
puerto cuenta con 350 empleados, y en el área de tours tiene a 200 empleados y guías; sin embargo, los pobladores de Mahahual se ven marginados de las ganancias del turismo de cruceros, ya que no se les permite el acceso a las instalaciones del muelle y la terminal.

Existen varios grupos de actores locales, como son los pescadores de cooperativas, los pescadores libres, los prestadores de servicios turísticos (sindicato de taxistas; dueños y empleados de establecimientos como cabañas y restaurantes), así como los comerciantes y los habitantes asentados en el kilómetro 55. Hay también prestadores de servicios y empleados de negocios turísticos relacionados con los cruceros, los cuales no habitan permanentemente en la comunidad, sino que residen algunos días a la semana. Como actores nacionales vemos el papel preponderante del Gobierno estatal a través de Fidecaribe y la Secretaría Estatal de Turismo, así como de representantes de otras secretarías quintanarroenses como Semarnat.

Existe problema de límites o de identificación de propiedad de la tierra desde 1997 por el Proyecto Costa Maya. Algunas de sus tierras pueden ser expropiadas por Fidecaribe, quien tomó posesión de los terrenos desocupados y acaparó los terrenos de las familias que no tenían papeles además de otros predios que eran terrenos nacionales.

Otro grupo de actores sociales que han entrado en escena recientemente son los inversionistas nacionales y extranjeros relacionados con el turismo de cruceros, específicamente las empresas privadas Promociones Turísticas Mahahual y Aviomar, los cuales prestan los servicios en la terminal, el transporte, y ofrecen los tours. Estos empresarios han adquirido predios de Fidecaribe en las zonas aledañas a Mahahual y han construido establecimientos en donde ofrecen distintos servicios (esnorkel, buceo, pesca, transporte, alimentos) a los turistas de los cruceros. Los habitantes locales perciben que estas empresas monopolizan los servicios y dejan a la comunidad pocas posibilidades de obtener ganancias.

En relación con los beneficios que obtienen los habitantes locales de los cruceros, nos comentan que lo único que se ha logrado es que más turistas visiten la comunidad los días que llegan los barcos, a pesar de que en el muelle les advierten "que no vengan al pueblo". Calculan que cuando llegan los cruceros visitan la comunidad aproximadamente 400 personas, que dejan ganancias a los restaurantes, las tiendas y los puestos de artesanías.

Las respuestas de los habitantes locales ante el fenómeno global del turismo de cruceros han sido varias. Un logro importante ha sido la creación de un sindicato de taxistas que tienen la exclusividad de transportar a los turistas fuera de las instalaciones de la terminal. También se han creado cooperativas turísticas, correspondientes a las cooperativas pesqueras existentes, y una nueva, llamada "Dorados de Mahahual", para ofrecer el servicio de tours de buceo a Chinchorro. Ya cuentan con barcos del tamaño reglamentario (29 pies) y el equipo necesario para llevar a los turistas a la reserva de Banco Chinchorro. Las 
autoridades de la reserva han restringido a estas empresas los tours de buceo y apoyan a las cooperativas turísticas locales para tener la exclusividad de brindar ese servicio en la reserva, como lo tienen las cooperativas pesqueras para la pesca.

Recientemente algunos habitantes locales han abierto nuevos restaurantes y está en construcción el hotel de un inversionista italiano. Hay también un considerable número de personas que se dedican a la venta de artesanías y joyería, básicamente, las cuales ponen sus puestos en la calle los días que llegan los cruceros. La mayoría de estas personas (puesteros) no son de Mahahual, sino que vienen de otros lugares como Cancún, Playa del Carmen y Tulum.

\section{Corredor Ecoarqueológico}

Las evidencias arqueológicas confirman el asentamiento de la antigua civilización maya en el extremo sur de Quintana Roo y Campeche a partir del período Preclásico hasta el Clásico Terminal, etapa en la que se construyeron diversas ciudades con un estilo particular de arquitectura denominado Río Bec. Este estilo arquitectónico tuvo una influencia regional de $85 \mathrm{~km}$ de norte a sur y 90 $\mathrm{km}$ de oeste a este, en el sureste de ambas entidades, lugar en donde se localizan más de 50 sitios arqueológicos, entre los que destacan Chicanná, Becán, Xpujil, Río Bec y Hormiguero, en Campeche, y Kohunlich, Dzibanché y Xinichná en Quintana Roo (Andrews, 1996: 16-19) (mapa 3).

Después de la conquista y durante la Colonia, las selvas del interior de Quintana Roo y Campeche fueron territorios inexplorados y de mínimo interés para los españoles ante la carencia de yacimientos minerales, además de que la práctica de la agricultura y ganadería requería mayor trabajo e inversión. Esta situación de abandono y olvido propició que los ingleses se introdujeran y explotaran los recursos de la selva en la cercanía del Río Hondo, principalmente de maderas tropicales y palo de tinte durante el siglo xvil y xvin, con la ayuda de los mayas rebeldes. En general, el territorio de la selva fue ocupado por poblaciones pequeñas con una distribución irregular y en constante movimiento, ante la escasez o agotamiento de los recursos, y como estrategia para evitar su localización y captura por parte de los españoles. Por otro lado, la difícil accesibilidad a la región propició su aislamiento y falta de control político por parte del gobierno central, lo que tuvo como consecuencia una pérdida de territorio, la insurrección indígena y la explotación de maderas sin beneficio (Dachary y Arnaiz, 1992).

A mediados del siglo xix, la selva del sur de Quintana Roo fue territorio refugio de los mayas que provenían del centro de la península a consecuencia del conflicto armado de la Guerra de Castas. Los rebeldes se internaron en la selva del extremo sur con el propósito de llegar al Río Hondo e intercambiar productos con los ingleses, principalmente armamento para la lucha contra el Ejército. El inter- 


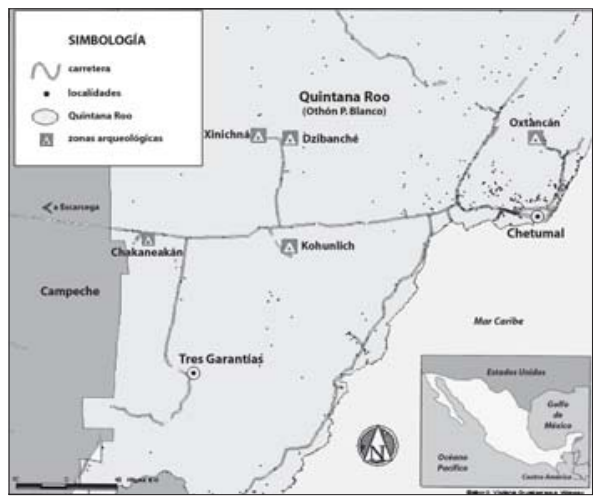

Mapa 3. Tres Garantías. Localización en Quintana Roo

cambio de armas también fue resultado de la concesión que los mayas otorgaron a los ingleses para la explotación de sus recursos forestales (Molina, 1995).

Ante esta situación, Porfirio Díaz otorgó por primera vez concesiones a empresas particulares de áreas forestales con el propósito de evitar el robo de maderas preciosas, mas no la explotación irracional, específicamente de la caoba y el cedro, de alta cotización en el mercado europeo. En 1904 decretó la creación del Territorio Federal de Quintana Roo, y dos años más tarde puso fin a la Guerra de Castas. A partir de 1917, en forma conjunta con la explotación de las maderas preciosas, se inició la extracción en grandes cantidades de la resina del chicozapote para su venta a los Estados Unidos.

El inicio del poblamiento de esta región del sur de Quintana Roo se remonta a la segunda mitad del siglo xix, cuando comienzan las concesiones forestales para la explotación de la selva. De esta manera el río Hondo se convierte en un centro aglutinador de población, al ser la vía fundamental para sacar las maderas preciosas de la selva. Las migraciones estacionales que se inician hacia el año 1915 son las de los primeros chicleros que llegan a esta zona de Quintana Roo provenientes de Veracruz, Chiapas, Yucatán o Belice, y comienzan en gran 
escala la explotación del árbol de chicozapote. Las actuales poblaciones tienen su origen en las centrales madereras y chicleras. A partir de 1983, han sido los ejidatarios quienes han manejado sus áreas forestales en esta zona, primero con el Plan Piloto Forestal (PPF), y actualmente con la Sociedad Civil de Productores Forestales Ejidales de Quintana Roo (SPFEQR). El PPF se inició como una propuesta de los ejidatarios y el Gobierno estatal para lograr aprovechar de manera íntegra y racional los bosques, además de iniciar un programa continuo de reforestación y mejorar la calidad de vida de los habitantes. Las principales acciones de la Sociedad, desde su fundación, han sido reducir la destrucción del bosque tropical y el aprovechamiento integral de la selva para beneficio comunitario. Hoy día 2100 familias de los ejidos de esta región se benefician de la actividad forestal. Uno de ellos es Tres Garantías.

\section{Tres Garantías}

Inició formalmente su poblamiento en 1973. Según el censo, para el 2000 la población total era de 820 habitantes, cuyos lugares de origen son Veracruz, Campeche, Yucatán, Tabasco, Quintana Roo, Chiapas, Morelos, Guerrero, Michoacán y Oaxaca.

Tres Garantías es una comunidad diversificada en recursos naturales y en actividades económicas: silvicultura, extracción de chicle, agricultura, apicultura, comercio, ganadería y, a partir del año 1991, el turismo.

La silvicultura ha sido y es la actividad económica estructurante de la localidad y la región circundante, por la ventaja comparativa de sus recursos forestales. La historia de la localidad es la historia de la actividad forestal regional, que se inició desde finales del siglo xIx, y a pesar de la intensa explotación de las maderas preciosas, aún se conservan importantes áreas de bosque tropical para su aprovechamiento. Actualmente el ejido de Tres Garantías pertenece a la SPFEQR, con resultados favorables de manejo y conservación de sus áreas forestales, que ocupan la mayor superficie del ejido si se considera que tan sólo $11 \%$ se utiliza para la práctica agrícola. El relativo éxito de la actividad silvícola de Tres Garantías es resultado de su superficie forestal, la infraestructura, el capital y su organización interna. El ejido tiene la ventaja de contar con un aserradero y un vivero que facilita las tareas de reforestación.

El antecedente inmediato de la actividad turística en Tres Garantías fue producto de alternativas de conservación, manejo y uso sustentable de los recursos naturales, y en particular de la fauna silvestre. Las ONG Biocenosis, Conservation International, la Fundación MacArthur y la Universidad Autónoma de Campeche hicieron una propuesta de turismo cinegético que fue de interés para los ejidatarios por la ventaja de las ganancias, pero también por la experiencia que tenían de la caza para autoconsumo. El objetivo del proyecto de turismo cinegético consistió en desarrollar una estrategia de manejo sobre especies de 
fauna silvestre en beneficio de las poblaciones locales. La SPFEQR, con el apoyo de estas ONG, realizó este proyecto de manejo y uso cinegético de la fauna de la reserva del ejido de Tres Garantías.

El área natural que se destinó para la actividad cinegética en el ejido de Tres Garantías era la reserva de fauna que los mismos ejidatarios habían delimitado con la intención de proteger los recursos naturales y aprovechar el espacio turísticamente. Los ejidatarios hicieron otra propuesta que consistió en un proyecto de ecoturismo, ya que la reserva contenía elementos que eran un atractivo para el turista de aventura, de observación de flora y fauna y los interesados en la antigua civilización maya por los vestigios existentes. Este proyecto complementaría el de turismo cinegético para aprovechar de manera integral la reserva y las instalaciones existentes, que consisten en cuatro cabañas construidas con mampostería y techos de guano, tres de ellas para el hospedaje de los turistas y una para los guías y las cocineras, además de una palapa que se utiliza como cocina y un baño.

Específicamente, los atractivos que se promueven en el ecoturismo de Tres Garantías son naturales: la flora y fauna de la selva, acompañados de elementos secundarios que otorgan interés y valor al destino, como los montículos arqueológicos, la convivencia con los habitantes y la visita a la localidad, que es un modelo en el uso sustentable de los recursos.

El caso de Tres Garantías es interesante porque combina la conservación de ecosistemas naturales con el desarrollo rural y porque considera el uso de los recursos naturales, que debidamente administrados conducen a la conservación con un esquema distinto al de las áreas naturales protegidas. Además se enfoca a un mercado específico de turistas interesados en la cacería, por lo que diversifica la oferta turística en la región.

La comunidad ha tenido apoyo de diferentes instituciones, programas y personas para el desarrollo del ecoturismo. Hasta ahora Tres Garantías ha sido pionero en el desarrollo de ideas, conceptos y experiencias. Ha costado trabajo señalar un camino y convencer a autoridades y a inversionistas de estos modelos de desarrollo. Particularmente difícil ha sido el abrir espacios legales para que la comunidad pueda ser beneficiaria de su fauna silvestre.

En el caso de Tres Garantías, los principales actores sociales vinculados al turismo son los ejidatarios miembros de la Sociedad de Productores Forestales Ejidales de Quintana Roo. Son los ejidatarios quienes ejercen el poder político en la comunidad y controlan los recursos naturales. Los avecinados se sienten en desventaja pues no tienen acceso a los recursos forestales, aunque cuentan con tierra para la agricultura.

La sólida organización comunitaria de Tres Garantías, basada en la figura legal del ejido, no se ha dado sin conflictos. Menciona uno de los ejidatarios fundadores que él ya no está de acuerdo con el ejido: "La gente se hace floja y se acostumbra a pedir. La tierra es de uno pero es de todos y no es de nadie. Los ejidatarios están tronados por esa mentalidad. Hay vicios creados por las leyes. 
Nosotros vamos a luchar de lo que estamos convencidos aunque tengamos que luchar con la asamblea."

Han existido problemas entre los miembros de la Sociedad, en particular con el proyecto de turismo, pues no han obtenido ganancias y sólo se han beneficiado las personas que están directamente involucradas en la reserva y trabajan cuando hay grupos de turistas. Existe la percepción entre los miembros de la comunidad de que el representante de la SPFEQR (y responsable del proyecto hasta 2002) no ha hecho un manejo eficiente de los recursos obtenidos y de que apenas se benefician unas cuantas personas. Incluso algunos ejidatarios tienen la idea de que funcionaría mejor un proyecto ecoturístico privado en sus tierras, desarrollándolo ellos mismos o vendiendo a inversionistas.

Otro grupo de actores son las ONG, tanto internacionales como nacionales, que han apoyado el proyecto en distintos momentos, como son Conservation International, la Fundación MacArthur, el Acuerdo México-Alemania (AMA), la Agencia de Desarrollo Británica (DFID) y Biocenosis. También las universidades de Quintana Roo y Autónoma de Campeche han brindado apoyo a Tres Garantías en cuanto a los estudios faunísticos de la zona y otros aspectos científicos. Otros actores sociales son las autoridades nacionales y estatales de distintas instancias, como son la Secretaría de Turismo Estatal y la de Desarrollo Urbano y Ecología (Sedue), además del Instituto Nacional de Ecología, que han brindado apoyo de distintos tipos y otorgado los permisos para el funcionamiento del proyecto.

Muchos habitantes desconocen el proyecto y se puede decir que la comunidad aún no se ha apropiado de él. Especialmente los jóvenes muestran desinterés en el ecoturismo y no ven este proyecto como una alternativa económica que les permitiera quedarse en la comunidad, por lo que muchos salen en busca de oportunidades de trabajo o para continuar sus estudios.

Los logros más importantes de este proyecto de ecoturismo han sido la conservación de los recursos naturales de la reserva comunitaria y el papel que ha jugado dentro de la educación ambiental de estudiantes de Quintana Roo y de otros estados de la República, sin embargo los beneficios económicos para los habitantes de Tres Garantías han sido muy escasos.

\section{Conclusiones}

Los resultados presentados sobre las comunidades estudiadas nos permiten plantear algunos temas de discusión. Vemos que la situación de las comunidades de la Costa Maya, Mahahual y Xcalak contrasta con la de Tres Garantías. La Costa Maya es parte del proyecto gubernamental de desarrollo regional, que se sustenta en una gran inversión de capital, mientras que el proyecto comunitario de Tres Garantías es ejemplo de un desarrollo turístico comunitario, surgido de la organización social creada a través del tiempo en la experiencia de la explotación forestal del PPF y de la SPFEQR y chiclera UPCN (Unión de Producto- 
res de Chicle Natural), apoyado por distintos tipos de organizaciones no gubernamentales. Sin embargo, en ninguno de los tres casos de estudio se ha conseguido aún el objetivo de lograr elevar la calidad de vida de los habitantes locales del sur de Quintana Roo.

Los datos recabados en la encuesta a hogares sobre la demografía, nivel educativo, infraestructura y servicios, actividades económicas, ingreso y, en particular, sobre el turismo en las comunidades estudiadas, nos permiten llegar a algunas conclusiones respecto a las diversas formas de integración de estas poblaciones al proyecto de desarrollo turístico sustentable del sur del estado.

En el cuadro 1 se presenta una síntesis de las características socioeconómicas de las comunidades estudiadas. Esta información se refiere al porcentaje de hogares que disponen de servicios como la energía eléctrica, el agua y fosas sépticas; a las principales actividades económicas a que se dedican los miembros de las familias, y al ingreso familiar. Con los datos obtenidos sobre las características de la vivienda (número de cuartos; materiales de construcción de pisos, paredes y techos; cuarto para cocina) se calculó un índice de adecuación de la vivienda en donde se llega a una clasificación de los hogares en pobres (P), carecientes (C) y los que cubren sus necesidades básicas (NBS). Hay que señalar que este índice sólo muestra la adecuación de las viviendas; no pretende hacer una evaluación más completa sobre la calidad de vida. Se presenta también el nivel educativo de la población mayor de 15 años, de acuerdo con la

Cuadro 1. Síntesis de las características Socioeconómicas de las Comunidades estudiadas

\begin{tabular}{|c|c|c|c|c|c|c|c|}
\hline COMUNIDAD & $\begin{array}{l}\text { Población } \\
\text { mayor de } \\
15 \text { años } \\
\text { (\%) }\end{array}$ & $\begin{array}{c}\text { Servicios } \\
(\%)\end{array}$ & $\begin{array}{l}\text { Activida } \\
\text { económi }\end{array}$ & & Ingre & & $\begin{array}{l}\text { Adecuación } \\
\text { de vivienda }\end{array}$ \\
\hline Xcalak & $\begin{array}{c}\text { analfabetos } \\
7.8 \\
\text { grado promedio } \\
6.1 \\
\end{array}$ & $\begin{array}{ll}\text { elect. } & 92.3 \\
\text { agua } & 46.2 \\
\text { fosa } & 76.9\end{array}$ & $\begin{array}{l}\text { pesca } \\
\text { turismo } \\
\text { agricultura }\end{array}$ & $\begin{array}{l}55.5 \\
11.1 \\
5.5\end{array}$ & $\begin{array}{l}1 \text { a } 2 \\
2 \text { a } 4 \\
4 \text { o }+\end{array}$ & $\begin{array}{l}37.5 \\
31.2 \\
25.0\end{array}$ & $\begin{array}{l}\text { P } 84.6 \\
\text { C } 7.7 \\
\text { NBS } 7.7\end{array}$ \\
\hline Mahahual & $\begin{array}{c}\text { analfabetos } \\
16.5 \\
\text { grado promedio } \\
5.4 \\
\end{array}$ & $\begin{array}{ll}\text { elect. } & 53.8 \\
\text { agua } & 7.7 \\
\text { fosa } & 61.5\end{array}$ & $\begin{array}{l}\text { pesca } \\
\text { turismo } \\
\text { agricultura }\end{array}$ & $\begin{array}{l}46.3 \\
7.7 \\
23.0\end{array}$ & $\begin{array}{l}1 \text { a } 2 \\
2 \text { a } 4 \\
4 \text { o }+\end{array}$ & $\begin{array}{l}57.1 \\
28.6 \\
0.0\end{array}$ & $\begin{array}{l}\text { P } 92.3 \\
\text { C } 7.7 \\
\text { NBS } 0.0\end{array}$ \\
\hline $\begin{array}{l}\text { Tres } \\
\text { Garantías }\end{array}$ & $\begin{array}{c}\text { analfabetos } \\
21.1 \\
\text { grado promedio } \\
3.7\end{array}$ & $\begin{array}{ll}\text { elect. } & 92.7 \\
\text { agua } & 80.5 \\
\text { fosa } & 82.9\end{array}$ & $\begin{array}{l}\text { agricultura } \\
\text { sivicultura } \\
\text { turismo }\end{array}$ & $\begin{array}{l}70.7 \\
7.3 \\
5.9\end{array}$ & $\begin{array}{l}1 \text { a } 2 \\
2 \text { a } 4 \\
4 \text { o }+\end{array}$ & $\begin{array}{l}56.1 \\
34.1 \\
7.3\end{array}$ & $\begin{array}{l}\text { P } 87.8 \\
\text { C } 2.2 \\
\text { NBS } 0.0\end{array}$ \\
\hline
\end{tabular}

Actividad secundaria.

FuEnTES: Encuesta a hogares y XII Censo general de población. 
información censal del año 2000, señalando sólo el porcentaje de analfabetos y el grado promedio de escolaridad.

Estos indicadores nos permiten ver que se trata de pequeñas comunidades rurales donde hay carencia de servicios públicos, sus pobladores tienen bajos ingresos familiares y, con base en la adecuación de la vivienda, puede decirse que la gran mayoría son pobres. El nivel educativo de la población adulta es bajo, ya que hay un considerable porcentaje de personas mayores de 15 años que son analfabetos, y el grado promedio de escolaridad no supera el sexto de primaria. Esta información muestra que hay un elevado número de habitantes locales que no tiene una adecuada calidad de vida.

Resulta interesante observar que en las tres comunidades estudiadas sólo un bajo porcentaje de sus pobladores se dedica al turismo, mientras que las actividades que sustentan la economía familiar de la mayoría son la pesca, en el caso de la costa, y en el caso de la selva, la agroforestería. Incluso en Tres Garantías el turismo apenas se reporta como una actividad secundaria.

La integración de los pobladores de Mahahual en el turismo se ha dado de forma individual con el establecimiento de pequeños negocios como restaurantes, cabañas, tiendas, así como ofreciendo servicios de actividades acuáticas como pesca deportiva, esnorkel y buceo. Sin embargo, no han contado con un apoyo gubernamental ni privado para poder incorporarse de forma directa al desarrollo turístico que actualmente empieza a tomar auge en la comunidad por los cruceros, sino que más bien hasta el momento han sido marginados de las ganancias generadas.

En Xcalak, son unas cuantas personas las que se benefician del turismo como guías, como empleados o como copropietarios en establecimientos turísticos.

Estos datos demuestran que la integración de los pobladores locales de estas comunidades al proyecto de desarrollo turístico regional no se ha dado aún de forma relevante. Queda claro, en la información presentada, que los beneficios económicos esperados del ecoturismo no se han concretado. Los factores locales que pueden influir en la incipiente integración de los pobladores locales al turismo, son el bajo nivel de educación y de ingresos de la mayoría de las familias. La información presentada nos hace ver la necesidad de poner en marcha más y mejores servicios educativos, de salud y sanitarios (basura, desalojo de aguas negras, tratamiento de aguas residuales), así como la urgente necesidad de programas de capacitación intensiva y de apoyos financieros, a fin de que los pobladores puedan integrarse de una manera más equitativa al proyecto de desarrollo regional de turismo.

Podemos observar en la información sintetizada en el cuadro 2 que las interrelaciones entre los diversos actores sociales que participan en el proceso de desarrollo regional, en particular en el Proyecto Costa Maya, son conflictivas debido a los intereses de cada uno de ellos en relación con el turismo y los recursos naturales. La tierra, el agua, la fauna marina, los arrecifes coralinos cons- 
Cuadro 2. Actores sociales en las comunidades de estudio en el sur de Quintana Roo

\begin{tabular}{|c|c|c|c|c|c|}
\hline COMUNIDAD & $\begin{array}{c}\text { Desarrollo } \\
\text { turístico }\end{array}$ & $\begin{array}{l}\text { Actividades } \\
\text { sociales } \\
\text { locales }\end{array}$ & $\begin{array}{l}\text { Actividades } \\
\text { sociales } \\
\text { nacionales / } \\
\text { estatales }\end{array}$ & $\begin{array}{c}\text { Actividades } \\
\text { sociales } \\
\text { internacionales }\end{array}$ & Problemática \\
\hline Xcalak & $\begin{array}{l}\text { buceo } \\
\text { pesca } \\
\text { deportiva }\end{array}$ & $\begin{array}{l}\begin{array}{l}\text { pobladores } \\
\text { nativos }\end{array} \\
\text { cooperativa } \\
\text { pesquera } \\
\text { pescadores } \\
\text { libres }\end{array}$ & $\begin{array}{l}\text { AUTORIDADES: } \\
\text { Fidecaribe } \\
\text { Secretaría de } \\
\text { Turismo } \\
\text { Semarnat } \\
\text { ONG } \\
\text { NACIONALES: } \\
\text { Amigos de } \\
\text { Sian Ka,an }\end{array}$ & 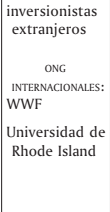 & $\begin{array}{l}\text { conflicto } \\
\text { entre locales e } \\
\text { inversionistas } \\
\text { extranjeros, } \\
\text { y entre estos } \\
\text { dos grupos y } \\
\text { Fidecaribe }\end{array}$ \\
\hline Mahahual & $\begin{array}{l}\text { buceo } \\
\text { pesca } \\
\text { deportiva } \\
\text { cruceros }\end{array}$ & $\begin{array}{l}\text { pescadores } \\
\text { libres } \\
\text { cooperativa } \\
\text { pesquera } \\
\text { prestadores } \\
\text { servicios } \\
\text { turísticos }\end{array}$ & $\begin{array}{l}\text { AuTORIDADES: } \\
\text { Fidecaribe } \\
\text { Secretaría de } \\
\text { Turismo } \\
\text { Semarnat } \\
\text { empresarios } \\
\text { nacionales } \\
\text { cruceros }\end{array}$ & $\begin{array}{r}\text { empresarios } \\
\text { extranjeros }\end{array}$ & $\begin{array}{l}\text { conflicto } \\
\text { entre locales } \\
\text { y empresarios } \\
\text { nacionales y } \\
\text { extranjeros } \\
\text { que controlan } \\
\text { los cruceros }\end{array}$ \\
\hline $\begin{array}{l}\text { Tres } \\
\text { Garantías }\end{array}$ & $\begin{array}{l}\text { cacería } \\
\text { ecoturismo }\end{array}$ & $\begin{array}{l}\text { SPFEQROO } \\
\text { ejidatarios } \\
\text { avecinados }\end{array}$ & $\begin{array}{l}\text { AuTORIDADES: } \\
\text { Secretaría de } \\
\text { Turismo } \\
\text { Sedue } \\
\text { INE } \\
\quad \text { ONG } \\
\quad \text { NACIonAlEs: } \\
\text { Biocenosis } \\
\text { Universidad de } \\
\text { Quintana Roo } \\
\text { Universidad } \\
\text { de Campeche }\end{array}$ & \begin{tabular}{|l}
\multicolumn{1}{c}{ ONG } \\
INTERNACIONALES: \\
Conservation \\
International \\
Fundación \\
MacArthur \\
Acuerdo \\
México- \\
Alemania \\
Agencia \\
de Desarrollo \\
Británica
\end{tabular} & $\begin{array}{l}\text { conflicto } \\
\text { interno entre } \\
\text { miembros de } \\
\text { la SPFEQROO }\end{array}$ \\
\hline
\end{tabular}


tituyen los recursos naturales más importantes a nivel económico tanto para los habitantes locales (pescadores, prestadores de servicios turísticos), las autoridades estatales y nacionales, así como para los inversionistas privados mexicanos y extranjeros que han participado en el desarrollo turístico.

Para los pescadores locales estos recursos naturales han sido sus principales medios de subsistencia por generaciones, no sólo para la satisfacción de sus necesidades básicas sino también para la generación de sus ingresos económicos. El deterioro de los recursos ocasionado por la sobreexplotación de algunas especies marinas ha hecho que se den cuenta de la necesidad de la protección ambiental y de buscar nuevas estrategias económicas a través del turismo.

Actualmente Mahahual empieza a beneficiarse del turismo, pero no a través de lo que se planteó como un proyecto de turismo sustentable, sino por los cruceros. Hay que considerar que este tipo de turismo no es sustentable, tanto por el impacto ambiental (contaminación, destrucción de arrecifes y otros ecosistemas en la construcción del muelle) como por la poca participación que pueden tener los habitantes locales, que, como anotamos, se han visto marginados por las empresas que manejan este negocio.

Existe también tensión entre los habitantes locales y los empresarios e inversionistas. La percepción de los locales es que son los inversionistas y los grandes empresarios quienes acaparan las ganancias del turismo. A su vez los inversionistas perciben que los habitantes locales no están capacitados para los trabajos en sus establecimientos, que no son buenos trabajadores y que no respetan la normatividad ecológica establecida. Estas tensiones son el reflejo de prejuicios culturales o actitudes racistas que surgen en la convivencia de los diversos actores en estas comunidades costeras. El desarrollo turístico llevado a cabo por los inversionistas a través de Fidecaribe se basa en la explotación de estos recursos, en especial las tierras del litoral, por lo que han adquirido un nuevo valor, generando la especulación. Hay que observar que también se han registrado incidentes entre Fidecaribe y los inversionistas en la Costa Maya.

Las autoridades del medio ambiente, nacionales y estatales, siguiendo los lineamientos de sustentabilidad planteados por las agencias internacionales, han desarrollado instrumentos de política ambiental en la región, como son el Ordenamiento Ecológico Territorial de Costa Maya, los esquemas de Desarrollo Urbano para Xcalak y Mahahual y los Planes de Manejo del Parque Arrecifes de Xcalak y de la Reserva Banco Chinchorro. Estas políticas han afectado los intereses de los demás actores sociales involucrados. Los pescadores perciben que se ha restringido su acceso a los recursos marinos y que las normas establecidas en las Áreas Naturales Protegidas (ANP) no se aplican de forma justa pues se privilegia a los inversionistas y empresarios. Por su parte, éstos también se sienten afectados por las restricciones que les imponen estas políticas en cuanto al desarrollo turístico.

Las organizaciones no gubernamentales, tanto internacionales como nacionales, han apoyado la creación de las ANP en la región y han dado asesoría y apoyo 
en cuanto al manejo de los recursos naturales siguiendo los planteamientos del discurso del desarrollo sustentable. Sin embargo, también ha habido problemática entre estas organizaciones, que han participado en la conservación ambiental, las autoridades encargadas del medio ambiente y los habitantes locales.

Los testimonios presentados nos permiten ver que en el desarrollo del proyecto Costa Maya se han creado varios conflictos sociales y que existen contradicciones con los planteamientos iniciales de sustentabilidad. Es claro que no se ha logrado aún incorporar a las poblaciones locales en el desarrollo turístico y la percepción generalizada es que más bien se les ha excluido del proyecto.

En Tres Garantías el ecoturismo representa actualmente una actividad económica alternativa para el aprovechamiento sustentable de recursos. La integración de sus habitantes al ecoturismo se ha dado como resultado de la organización interna de la comunidad y de la experiencia en la silvicultura social, sin embargo, hemos visto que son pocos los habitantes que logran beneficiarse de esta actividad. La comunidad ha tenido apoyo de diferentes organizaciones, instituciones gubernamentales y personas para el desarrollo del ecoturismo, pero a pesar de estos apoyos, el ecoturismo no ha podido aún despegar en el sur del estado como una actividad económica con las ventajas señaladas inicialmente para el desarrollo sustentable de Quintana Roo (Quinto, 1998).

Los resultados presentados nos permiten concluir que un aspecto esencial de las comunidades es su heterogeneidad. Resulta evidente que incluso en estas comunidades pequeñas hay divisiones no sólo en cuanto a edad, parentesco y género, sino diferencias económicas, políticas y sociales. Hay diferencias en cuanto al poder político y el acceso a grupos de poder externos. La heterogeneidad socioeconómica, la inequidad y la diversidad de intereses entre los múltiples actores tienen implicaciones en el acceso y uso de recursos naturales.

Es importante señalar que existe una coincidencia en todas las comunidades en cuanto a la percepción positiva sobre el turismo, como una posible actividad generadora de ingresos, sin embargo, también existe la percepción generalizada entre la mayoría de sus habitantes de que no se benefician de ella. Piensan en el turismo como una actividad que en el futuro pueda brindar oportunidades de trabajo para los jóvenes, cuya incorporación a las actividades turísticas en sus comunidades podría evitar la deserción escolar y la migración de algunos de ellos.

Por las características socioambientales de la Costa Maya podemos predecir que una actividad turística intensa y la afluencia masiva de inmigrantes, que conlleva un elevado crecimiento poblacional, pueden causar daños negativos irreversibles tanto en el medio ambiente natural como en la calidad de vida de los habitantes de la región.

En el caso del Corredor Ecoarqueológico, la vinculación de las comunidades con la industria global del turismo se ha dado de una manera muy distinta que en la costa, tanto por aspectos socioculturales como ambientales de la zona, 
por lo que podemos observar que la situación de Mahahual y Xcalak contrasta con la de Tres Garantías.

Como ya se mencionó, la Costa Maya es parte del proyecto gubernamental de desarrollo regional, sustentado en una gran inversión de capital, mientras que el proyecto de Tres Garantías es ejemplo de un desarrollo turístico comunitario, surgido de la organización social creada a través del tiempo en la experiencia de la explotación sustentable de los recursos forestales por medio del Plan Piloto Forestal de la Sociedad de Productores Forestales Ejidales de Quintana Roo y de la Unión de Productores de Chicle Natural. Se trata de una experiencia de silvicultura social basada en la fuerte organización social de los ejidatarios.

Frente a la globalización, las localidades son capaces de movilizarse y proyectar los intereses de sus miembros más allá de su círculo social. Por lo tanto, no son simples receptáculos de las fuerzas globales, sino que están activamente involucradas en su propia transformación. Hemos visto cómo los pescadores y los campesinos del sur de Quintana Roo están tratando de integrarse con distintas estrategias al proyecto regional de desarrollo sustentable.

La información analizada nos permite ver que la incorporación de comunidades locales al proyecto turístico de desarrollo regional en el sur de Quintana Roo ha demostrado no darse de una manera sencilla ni mecánica, y puede llegar a generar varios problemas, más que lograr los beneficios ambientales y sociales esperados. Algunos de estos problemas son la tensión social que existe por la apropiación de los recursos, en particular la tierra, así como de los trabajos, por parte de los actores sociales que sustentan el poder económico y político. Las autoridades estatales han creado una serie de políticas para dar prioridad al apoyo y beneficio de la industria turística en todas las instancias gubernamentales. Se ha creado una serie de incentivos para aumentar el interés de los inversionistas y empresarios privados, favoreciendo sus intereses sobre los de la población local.

Hemos mencionado que el desarrollo sustentable es una nueva estrategia de apropiación de los recursos, basada en políticas intervencionistas en nombre del medio ambiente. Las agencias internacionales, como la Organización de las Naciones Unidas, el Banco Mundial (BM) y el Fondo Monetario Internacional (FMI), imponen principios, reglas y controles totalmente intervencionistas, que son los que rigen los nuevos procesos globales de desarrollo. El BM y el FMI se convierten en organismos de orientación y control de las políticas internas de los países, con alta influencia en las legislaciones locales, e imponen una serie de principios rectores para colocar a los países en el camino del desarrollo sustentable (Riquelme, 2000).

En México, estos principios se han aplicado estableciendo políticas que responden a los lineamientos de estas agencias internacionales, como son los planes de desarrollo turístico y las políticas de protección ambiental, tanto nacionales como estatales, en donde la sustentabilidad es una prioridad. Como 
vimos, en Quintana Roo la planeación de la actividad turística está basada en el turismo sustentable como "el principal motor de su desarrollo económico". Siguiendo los lineamientos de agencias internacionales, se han enfatizado los derechos de propiedad y la ganancia privadas sobre los intereses comunitarios. Son los inversionistas privados, tanto extranjeros como nacionales, quienes se han apropiado de los recursos obteniendo los mayores beneficios del turismo. En general, podemos decir que no ha habido el respeto a las poblaciones locales en el desarrollo turístico del estado que permita llegar a una verdadera sustentabilidad. No se puede hablar de turismo sustentable mientras las condiciones de vida de muchos de los habitantes locales sean deficientes. La prevalencia de la pobreza entre muchas de las familias de las comunidades estudiadas nos muestra que hasta ahora el turismo no ha logrado elevar la calidad de vida de todos los habitantes locales, además de que se ha acentuado la desigualdad social dentro de las comunidades. Es decir, que el desarrollo del turismo ha sido socialmente inequitativo en la distribución de las ganancias.

El ecoturismo puede ser parte de un enfoque diversificado para lograr el desarrollo sustentable, sin embargo, continúa siendo básicamente un concepto teórico, quizá demasiado ambicioso o complejo para alcanzarlo, dada la contraposición de intereses que incluye (Boo, 1995). Cualquier desarrollo ecoturístico tendrá una mezcla de beneficios y costos. Como hemos visto, los beneficios para un grupo de actores sociales pueden representar costos para el otro.

Para muchas comunidades la integración al mercado global del turismo no es una transición fácil. Para lograr integrarse necesitan entender qué es el ecoturismo, capacitación en desarrollo y administración turísticos; necesitan acceso a financiamiento para pequeñas empresas. Es importante que los trabajos en el ecoturismo representen para los pobladores locales empleos estables, justos y de largo plazo. La idea del ecoturismo como parte esencial del desarrollo sustentable en el sur de Quintana Roo continuará siendo una hipótesis hasta que haya mayor evidencia de su validez para la conservación ambiental y en cuanto a la mejoría de la calidad de vida de la población local.

El turismo es una fuerza económica tan poderosa que ha posibilitado una transformación radical, socioeconómica y demográfica, del estado de Quintana Roo en apenas unas décadas; sin embargo, la planificación de esta industria debería hacerse pensando en que existe un límite ecológico y social para su futuro desarrollo. Los ejemplos en el sur de Quintana Roo nos permiten ver que los nuevos proyectos de desarrollo planteados con base en el discurso de agencias internacionales, como el Banco Mundial, imponen reglas y controles totalmente intervencionistas, de tal manera que se puede concluir que el desarrollo sustentable es una nueva estrategia de apropiación de los recursos, basada en una ideología que legitima las políticas intervencionistas en nombre del medio ambiente. Estos principios son los que rigen los nuevos procesos globales de desarrollo. 
Hay indicaciones actuales que sugieren que la globalidad persistirá en el futuro inmediato y que una más intensa globalización está por venir. En conclusión, podemos decir que no todos disfrutan del mismo acceso o de una voz semejante en el proceso de globalización. Las dimensiones que la mundialización ha traído a las relaciones sociales nos llevan a centrarnos en los retos éticos presentes: la justicia social y la integridad biosférica, es decir, en el desarrollo de una nueva ética socioambiental.

\section{BIBLIOGRAFÍA}

Andrews, George

1996 "Arquitecturas Río Bec y Chenes", Arqueología Mexicana, III (18): 16-25, México: Editorial Raíces / INAH.

Arnaiz Burne, Stella Maris

1992 "El turismo y los cambios de la globalización", en Quintana Roo: los retos del fin de siglo, pp. 75-100, A. C. Dachary, D. Navarro y S. M. Arnaiz. Chetumal: Centro de Investigaciones de Quintana Roo.

Boo, Elizabeth

1990 Ecotourism: The Potentials and Pitfalls. Pensilvania: World Wildlife Fund y U. S. Agency for International Development, Wickersham Printing, 2 vols.

1995 "Introducción al ecoturismo", Manual de Desarrollo Económico Compatible, pp. 1-11, Arlington, Virginia: Ecoturismo / The Nature Conservancy.

Brandon, Katrina

1993 Bellagio Conference on Ecotourism. Bellagio, Italia: Rockeffeller Foundation.

1995 Ecotourism and Conservation: A Review of Key Issues. Environment Department Papers, Washington: The World Bank (Paper no. 033).

FIDECARIBE

1999 Costa Maya. Un nuevo destino. Quintana Roo, México: Fideicomiso del Caribe, Quintana Roo, México.

2002 "In need of new ennvironmental ethics for tourism?", Annals of Tourism Research, 30 (1): 94-108. Reino Unido: Pergamon Press.

Ianni, Octavio

1999 La sociedad global. México: Siglo XXI.

INEGI

2000 XII Censo general de población y vivienda 2000. Quintana Roo. Resultados definitivos, datos por localidad (integración territorial). México: INEGI. 
INEGI

2000 XII Censo general de población y vivienda 2000. Quintana Roo. Tabulados básicos. México: INEGI.

Martos, Luis Alberto

2002 "La costa oriental de Quintana Roo", Arqueología Mexicana, IX (54): 26-33. México: Editorial Raíces / INAH.

Molina, Virginia

1995 Los mayas y los recursos de la frontera sur de México. México: Centro de Ecología y Desarrollo.

Quinto, Francisco

1998 "El ecoturismo en Quintana Roo: Un compromiso con la cultura y con el medio ambiente". Quintana Roo: Universidad de Quintana Roo (mecanografiado).

Riquelme, Graciela

2000 El Banco Mundial, mujeres y educación. Aislamiento, crítica o negociación. Uruguay: Red de Educación Popular entre Mujeres de América Latina y el Caribe.

Rosado May, Francisco et al.

1998 Programa de ordenamiento ecológico territorial de la región Costa Maya. Chetumal: Costa Maya / Universidad de Quintana Roo.

Salas, Hernán

2002 Antropología, estudios rurales y cambio social. La globalización en la región lagunera. México: UNAM, Instituto de Investigaciones Antropológicas.

Scholte, Jan Aart

1997 Globalization and Social Change. Warwick: University of Warwick (mecanografiado).

Teo, Peggy y Lim Hiong Li

2003 "Global and local interactions in tourism", Annals of Tourism Research, vol. 3 (2): 287-306. Reino Unido: Pergamon Press. 